\title{
Women's Participation in Water Resource Management, in Case of Enderta District, Tigray Region, Ethiopia
}

\author{
Amleset Gebreegzabher \\ Department of Geography and Environmental Studies, Mekelle University, Mekelle, Ethiopia \\ Email: a mleset.gebreegzabher@mu.edu.et
}

How to cite this paper: Gebreegzabher, A. (2018) Women's Participation in Water Resource Management, in Case of Enderta District, Tigray Region, Ethiopia. Journal of Water Resource and Protection, 10, 1047-1060. https://doi.org/10.4236/jwarp.2018.1011061

Received: February 12, 2018

Accepted: November 2, 2018

Published: November 5, 2018

Copyright $\odot 2018$ by author and Scientific Research Publishing Inc. This work is licensed under the Creative Commons Attribution International License (CC BY 4.0).

http://creativecommons.org/licenses/by/4.0/

(c) (i) Open Access

\begin{abstract}
Women's participation in each and every activity of a country is crucial. Especially to achieve the sustainable development goals involvement of girls and women in each sector of a nation contributes more and more. Considering women as family leaders; in many cultures in the household responsibility, taking care of their husband and children they are nation builders. However, participation, interaction and contribution of women outside of their house are not significant. Above all, in science and technology related matters their involvement is very weak. Therefore, this study deals with examining women's participation in water resource management in Endertaworeda, specifically in Didba and Shibta sub-districts. The study result indicated that, the role of women in water management is high, especially in domestic level and the willingness to participate in external water issues was increased, but the decision making power never reached equality between men and women. The analysis shows that even though there are few women in the water committee of the local community and the water resource management sector, still their participation in decision making is insignificant. Even today, the society confirms the supremacy of men over women. As a result the policy at national levels as well as the regional level which emphasized on women's participation in water resource management has become elusive its implementations. On the evidence of the study results, there are different barriers for women's participation in management. The most frequently mentioned barriers are socio-cultural barriers, women's low educational success and access in the country and low number of women in the office as managerial staff. Therefore, measures should be taken to enhance women's participation in management position.
\end{abstract}

\section{Keywords}

Sustainable Development, Family Leader, Nation Builder, Water Issues, 
Barriers

\section{Introduction}

There is widespread recognition that the world is facing a growing water crisis, affecting the well-being of millions of the poorest people. Rapidly growing populations, urbanization, agricultural intensification and climate change (such as global warming) all contribute to greater competition and scarcity of water resources [1]. The earth which holds more than 300 million cubic miles of water [2] beneath the land surface and on the surface and in the atmosphere is increasing the water shortage as a result of mismanagement. This mismanagement is related with faulty approach. Water as a common capital needs common consciences among the stakeholders. Participation of users in decision-making produces more efficient and more sustainable projects. When communities influence or control the decisions that affect them, they have a greater stake in the outcomes and are more committed to ensuring success. Participation helps to break down the cycle of dependence which characterizes much top down development work [3].

Consequently, taking into account the closest water user in a community; conferences, meetings and summits decide that water management should be gender sensitive approach which focuses on women and gender equality. In line to this, the Dublin principles which amended after a consecutive conferences and meeting discussions were noticed that "There should be recognition that women play a central role in the provision, management and safeguarding of water".

Currently, though, it was evidenced that the role of women in water management is high, especially in domestic level and the willingness to participate in external water issues was increased, the decision making power never reached equality between men and women. There are few women in the water committee of the local community and the water resource management sector, still their participation in decision making is insignificant. Therefore, making water resource management gender approach is important to fill the gap.

\section{Statement of the Problem}

Being one of the most important key elements influencing public health, wellbeing, the preservation of ecosystems and the economic development of a country, water is a natural, yet limited resource indicates that it is "under pressure" [4]. Thus, planning, management and preservation of water is essential. Fundamental to water resource planning and management is an understanding of the availability of water and a notion of how much of it will be needed, in what quantity, for how long and for what purposes.

In addition to the above fundamentals, there is also a need to understand the actors in water use. 
It is understood that, women are the closest actors for water. As a result the ties between women and water are numerous yet they face considerable inequality, such as limited access to important positions of decision making in water related issues. Only some are recognized by mainstream culture or activism, the ways in which women are tied to water are often used as ways to promote the adoption of sustainable water practice. Gathering, storing and using water takes up the majority of the day for many women throughout the developing world.

However, Women's participation in decision making and as water resource managers is uncommon. Because of the traditional attitudes and beliefs of the society, Household water provision is still a female responsibility in most African societies, especially in the rural areas [5].

Like those of other African countries, Ethiopian women are not significant decision makers in almost all water management issues. It's not because they are less efficient, but because they have limited access to necessary inputs, as a result of those various cultural norms. The earlier perceptions on the profile of a person who thought to be most likely effective leader led to the assumption that the ideal leader is a man.

In fact, even today many people assume that men can lead and women cannot, based on the argument that women cannot make full time open ended commitment to their careers. This assumption has its own impact on the role of women in water resource management.

Potable water supply coverage is still only $22 \%$ in rural Tigray [6]. As a result, the distance traveled and time taken to fetch water has negative consequence for health and for economic productivity. The main burden to feed families and negative impact tends to fall on women, who are traditionally responsible for maintaining the household water supply and on their children. Hence, the Relief Society of Tigray (REST) tries to minimize the burden on women and to maximize their participation on water issues. However, the program has problems in its implementation and it is not achieving what it had intended in terms of "improving women's social status and traditional role structure in water management".

Consequently, if the intended program was not achieved and women's were remain backward from modern achievements and roles in the water management it needs a study to identify and improve the barriers that hinder the programs achievement as well as women's participation. Endertaworeda, southern administrative zone of Tigray, is the site for the study. Water for human consumption is collected from deep wells; shallow hand dug wells, springs and minor rivers. Like other parts of Tigray, water for household is collected by women and girls. Similarly, women's role in water issue remains collecting, storing and using for various purposes rather than to participate in decision making. So, the study tries to find out the status and participation of women in water resource management in Endertaworeda as its result may help to create a general overview about the status of women society, especially in relation to water and women in Endertaworeda. 


\section{Material and Methods}

\subsection{Background of the Study Area}

Enderta is one of the 36 districts in Tigray Region of Ethiopia and is one of the drought prone and chronic food deficient districts in the region. It is bounded by Hintalowajerat in the South, Samre-seharti and Degua-tembien districts in the West, Wukro district in the north Afar Region in the east. Geographically, the district is located between $13^{\circ}-14^{\circ}$ north and at $39^{\circ}-40^{\circ} 30^{\prime}$ east. The district covers a total land area of 1446.49 square kilometers (Figure 1).

\subsection{Research Design and Methodology}

The study employed both qualitative and quantitative research methods. The target population which used for this study was dwellers of the selected villages and key officials from Enderta district department of water resource management. In addition, the researcher used a descriptive study design to show the status of women's participation, factors which affect women participation and measures to be taken to improve women's participation in water resource management among the residents of selected villages.

To do this, the study used both primary and secondary data sources. The primary data was collected using questionnaire, interview, focus group discussion and observations. The secondary data were collected from journals, articles, proclamations, policies, guidelines etc.

\subsection{Sample Size and Sampling}

Enderta district has 69 sub-districts. Because of that, the researcher used a cluster sampling technique. First, the researcher selected two Tabia (sub-district) out of sixty nine sub-districts. Secondly, one village was selected purposively from each two sub-districts (Meremety and Shafat) based on the various activities of water resource development activities (Figure 1). Therefore in this study, data were collected from a total sample of 120 and three concerned officials of water sector and project group. Moreover, 12 individuals were participated during the focus group discussion. The target population was selected using simple random sampling.

\subsection{Procedures of Data Collection and Analysis}

Before administering the questionnaire, it was translated in to Tigrigna to make communication easier. Additionally the researcher employed two data collectors who took intensive training on how to collect it. As a result, the questionnaires were distributed and collected by the enumerators in each village. In addition, observation was used to triangulate the data collected by questionnaire and interview. The interview, observation and document analysis was carried out by the researcher.

After that, all the responses obtained from key informant interviews, the focus group discussions and the open-ended questions included in the questionnaire 


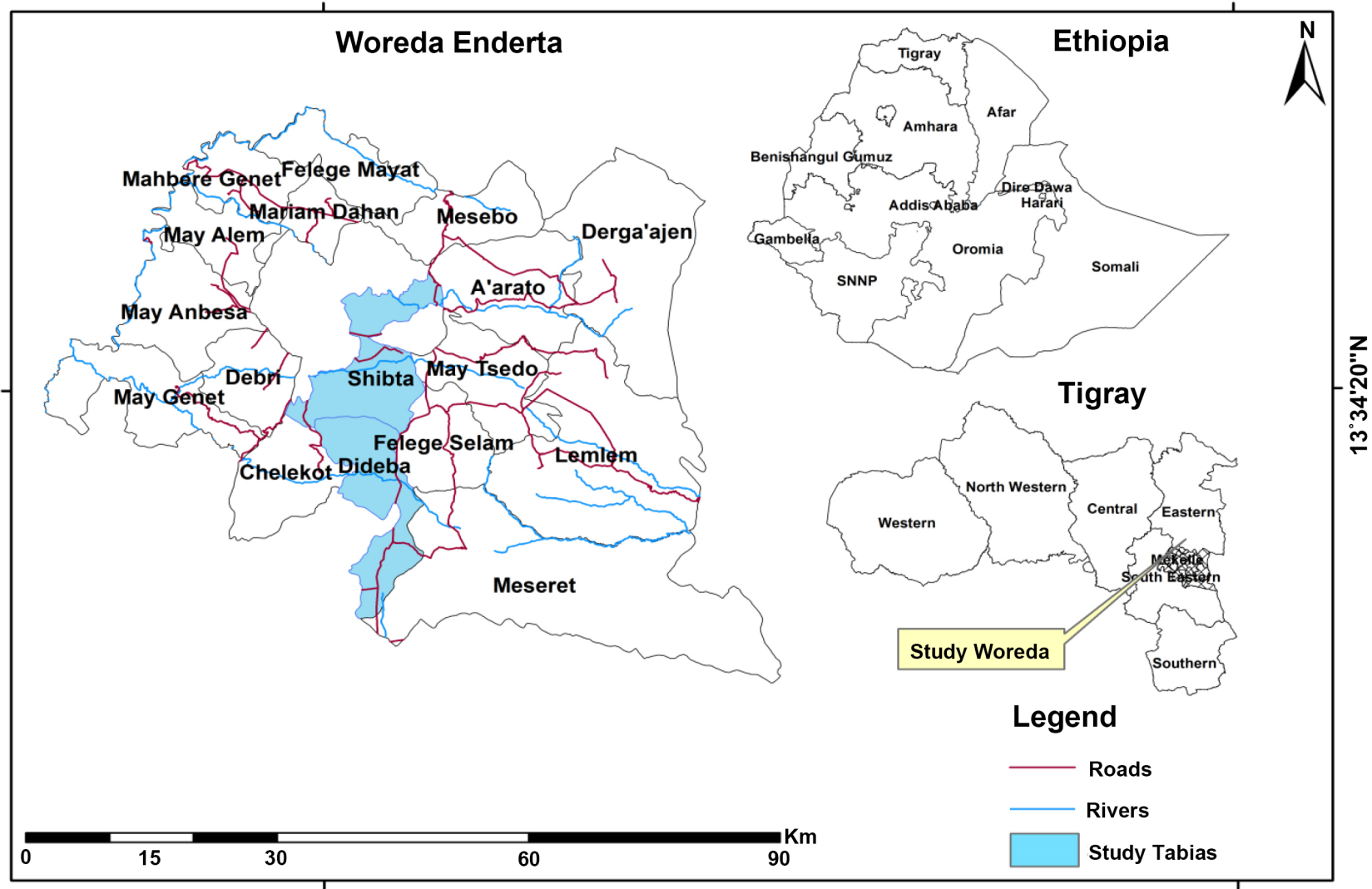

Figure 1. Map of the study area.

were analyzed using the simple analysis technique. To help showing the clear picture of the situations some of their verbatim are quoted directly. In regard to the quantitative data analysis, the generated data were presented in terms of tables and percentages that could reflect the true nature of information collected from respondents.

\section{Results of the Study}

Responsibility of fetching water is for women and girls in the study area. Many walk long distance spending hours per day burdened under heavy containers and suffering acute physical problems. On average they spend 30 minutes to fetch from hand pump and 50 minutes from river for round. Not only that, also they may spend more than an hour in queue.

As shown in Figure 2, girls in Meremety have spent their time and energy in queue to fetch water for more than an hour. When the researcher arrived there and captured the photo the time was around 6:30 in the morning though the girls were arrived there before an hour. Therefore, it was girls who fetch water and the most vulnerable group with the absence of water. However, the study result from interview, observation and distributed questionnaires indicated that limited participation of women during planning, administration and management of water resource. 


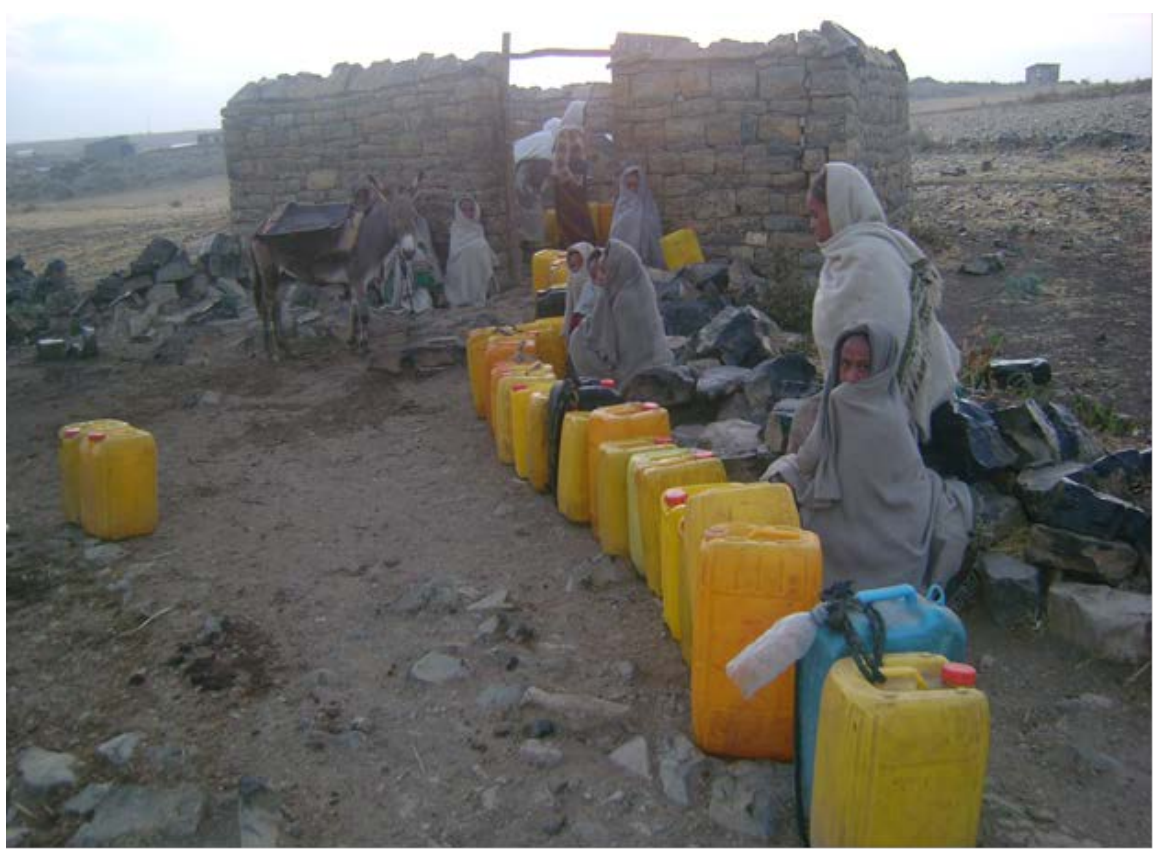

Figure 2. Girls and young women's queue to draw water; photo taken from Meremety.

\subsection{Factors Affecting Women's Participation in Water Resource Management}

Women's problem is deeply rooted in the imbalance between what women do and what they have. In most cultures, women must have acquired the skills necessary to do household works; like cook food, wash cloth, take care of family and the likes. As a result, the respondents (100\%) in both study area replied that socialization is a major factor that contributes to have a low participation of women in water resource management (Table 1). Besides, the interview result noted that the way that make women's behave in the society and acceptance is highly influenced the participation of women in external activities. Similarly, [7] stated that, in most societies, women lack experience of decision making and management in the public area because girls, in contrast to boys, are socialized to passive roles and given little opportunity to make decisions or develop management skills outside the family context. Besides, [8] pointed out that, women have been socialized in to believing that they do not deserve senior positions. In concurrent the respondent noted that, the folks and proverbs in society discourage the inspiration of women in a field. For instance;

A house constructed by women is collapsed when a hyena shouts.

The presence of women to work together result in damage.

No matter the wisdom of a woman, the decision is to the man.

The trust in women is just as to hold a cloud and the like shows that how women's work invalidates by their society and demoralized them. Moreover, in some parts of Ethiopia, women are excluded from ploughing and threshing crops because of the myth that women's involvement will reduce production. All 
Table 1. Socio-cultural barriers.

\begin{tabular}{ccc}
\hline \multirow{2}{*}{ Barriers for women's participation } & \multicolumn{2}{c}{ Degree of agreement } \\
\cline { 2 - 3 } Socialization in the family and society & High $\quad$ Medium Low \\
Household responsibilities & $\checkmark$ & \\
Reproductive responsibilities such as giving birth, child care and others & & $\checkmark$ \\
\hline
\end{tabular}

these have far reaching implications on women's social space and the question of social justice and empowerment.

In addition to socialization, the role of women in water resource management is negatively influenced by their household responsibility (Table 1). As it is understood from different interview, women's most important role in water management in the traditional context is seen within the domestic arena like that of domestic water managers. In this role they are seen as responsible for the gender-specific tasks of procuring, managing and using water for domestic purposes.

The respondents pointed out that, it is clear that in most circumstances, women are more likely than men to spend their incomes, energy and time on meeting their family's requirements. Thus, women became responsible for household strategies and are obliged to manage those household resources under their control to ensure the survival and well-being of other household members.

However, it is important to go beyond family responsibility to improve their capacity, contribution and participation in water resource management and other sectors.

Besides, the effect of reproductive responsibilities is not negligible. Governments and donors usually see women's involvement in water-resource management primarily from the perspective of their roles in social reproduction. However, the primary concern of women is for activities which make them acceptable by society as a good women i.e. the way what they socialized. As a result, income-generating activities have been added to the projects to make them more attractive to women. In fact, 325 women received training on water and sanitation, maintenance and operation in 2009. Though, the participation of women have not changed that much as a result of the socio-cultural roles and activities which consuming their time and reduce their external roles.

Educational factors that affect women's participation in management are basically related with the socio-cultural barriers for women's advancement in the public activities of the country. Though, Low educational qualification is another factor that has high contribution in decreasing the participation of women in water resource management (Table 2). Despite recent improvement of females' education, females' low educational access and success in the country is the fundamental barrier for employment and management position in water resource management. It was indicated that, even though some girls got opportunities to 
Table 2. Educational barriers.

\begin{tabular}{ccc}
\hline \multirow{2}{*}{ Barriers of women's participation } & \multicolumn{2}{c}{ Degree of agreement } \\
\cline { 2 - 2 } & High & Medium Low \\
\hline Low educational qualification & $\checkmark$ \\
Lack of knowledge about water technology & $\checkmark$ \\
\hline
\end{tabular}

participate in education, their success in education still lag behind that of boys because of socio-cultural factors, particularly gender division of labor and the negative attitude of the society and the family towards girls' education. As the result of this, there is low number of women in management staff, which in turn resulted in gender inequality in the management positions of water resource and energy bureau. In other way, lack of knowledge about water technology has an impact on the role of women in water resource management (Table 2).

Additionally, there are institutional factors such as patriarchal culture of the society, gender discrimination during appointment and the recruitment criteria (Table 3). The study reviled that, still the society believed on the idea of "appropriate place or work for women is at home". Women who spent her time out of home don't get respect when it compare to the one who stay at home. Here, the matter is social value, which is the larger concept which includes social capital as well as the subjective aspects of the citizens' well-being, such as their ability to participate in making decisions that affect them. Women whose stay at home and give her life and time to her family without take carrying outside is getting those social capitals in the study area.

On the other hand, by taking in to account the reproductive responsibility (child rearing) and their dual responsibility; organizations do not have that much interest to heir women/female applicants. Because they believed that, women are not interested to do a job which is far away from their house especially if they have children. Some what it is true but this is a social constructed behaviour not natural and it can be eliminated with changing social attitudes on women and their identified role.

Besides, the recruitment criteria which one set down based on the qualification and the rank of men plays grate role on women's to lag behind. Women were excluded from any participation in leadership activities for a long time. Now days, including women in any and each practice of project and community is mandatory and even becomes a means to win. However, the problem is that including women just for in saying and for not losing the winning opportunity.

\subsection{Other Factors That Affect Women Participation in Water Management}

Women's multiple roles and patriarchal relationships do not give them a chance to be in the informal network of men and having opportunities to be selected for management positions. [9], revealed that even where there is an acceptance of equal opportunities there are implicit disadvantage, in which men had more 
Table 3. Institutional barriers.

\begin{tabular}{cc} 
Barriers of women's participation & \multicolumn{2}{c}{ Degree of agreement } \\
\cline { 2 - 2 } $\begin{array}{c}\text { Patriarchal culture of the office } \\
\text { Gender discrimination during appointment }\end{array}$ & $\checkmark$ \\
\hline $\begin{array}{c}\text { The recruitment criteria, which one set down based on the } \\
\text { qualification and the rank of men }\end{array}$ & $\checkmark$ \\
\hline
\end{tabular}

fully developed informal networks in different occasions between colleagues and used them for their career development whereas women are excluded from where networking takes place, thus they miss a lot of what is gained through this process. If women are able to be in the informal network of men, they might have the opportunities to be nominated for the managerial position.

Women's have had informal network, the reason that influence women's participation is lack of place to discuss about their problems rather their concern is all about their family and social problems without gender difference. Women's being passive in organizing themselves is partly due to the way how the implementation process of the management interventions is arranged. Consequently, managing water in an integrated and sustainable way can actually improve gender equity by easing access, both to water and to related services [10]. In many ways, formal and informal women's networks can play important and stimulating roles.

In addition to informal network, lack of support and encouragement by the husband and family, absence of role models and mentoring, absence of encouragement from governmental and non-governmental organizations, lack of confidence and religious burden are other factors.

Lack of opportunity to see other women in a variety of management positions to hear how these women describe their lives and to compare themselves with women just one step further up the hierarchy have been mentioned as reasons for women not to have moved in to management positions in larger numbers. Therefore, as the research result indicated, the absence of role models and mentoring has adversely impacted on having large number and effective women participation in water resource management. The Focused group participants stated that, limitation of training which sponsored by government and lack of funding for women to participate in all water related issues was influenced women's participation. So, according to the study results, the absence of support and encouragement from governmental and non-governmental organizations has its own impact.

Moreover, lack of confidence is one of the negative influential factors on women's participation. As the interviewees said, women have an indigenous knowledge how to do things with water inside their house; they lack a confidence since the water technology is changed in the external activities of water related issues. 


\subsection{Measures to Enhance Women's Participation in Water Resource Management}

Even though the elimination of cultural barriers is challenging, to enhance women's participation in water resource management is the first and best option ( $98 \%$ of the respondents agreed). Each factor which mentioned above is mainly the results of socio-cultural barriers.

In addition to the elimination of socio-cultural barriers, $93 \%$ of the respondents in both study area agreed that, changing the attitude of society is another measure to enhance women's participation. However, as the interviewees explained, changing society attitude might be challenging, because society's attitude is related with socio-cultural situations and according to [11], systemic discrimination against women in the norm and that norm will not change rapidly. As a result, the interviewees underlined that, there is a need for legal reforms to promote women's equality and to protect their interests against gender-based cultural practices.

Besides, $100 \%$ of the respondents agreed on the importance of "increasing women's educational qualification" as a measure to enhance women's participation in management.

Girls' Education has been recognized as panacea to sustainable social development across the globe. In fact, girls' education is considered to be a pivotal element of empowering them [12]. In the literature of gender and development, girls' education is identified as the precondition of balanced and equitable socio-economic development. Current studies depict the enrolment of women to primary school is increased. However, their number becomes decrease and decrease from high school to higher educational institutions in developing countries. Consequently, bring low women's educational status below the rank of leadership.

Once again, $98 \%$ of the respondents noted that, giving gender sensitive training for the community could improve the participation of women and reduce the attitude of the society in general. Similarly, 95\% of the respondents agreed with the method of "encouraging women to participate in management positions" as additional measure to be taken to enhance women's participation in water management. Table 4 indicated that $93 \%$ of the respondents pointed out that "creating opportunities for women to observe major water committee activities-purposeful involvement of women in water commission and senate meeting" are important measures. In addition to that, $100 \%$ of the respondents in the study area stated, developing women's management skills are other measures to be taken to enhance women's participation in water resource management. According to the interviewees, developing women's management skill is important even though women are visible to be active and responsible for their management roles as well as management styles. In the absence of management skill, they might be overwhelmed by men who have life long experience in relation with public roles. 
Table 4. Measure to be taken to enhance women participation.

\begin{tabular}{|c|c|c|c|c|c|c|}
\hline \multirow{3}{*}{$\begin{array}{l}\text { Measures to enhance } \\
\text { women's participation }\end{array}$} & \multicolumn{6}{|c|}{ Level of agreement } \\
\hline & \multicolumn{2}{|l|}{ Agree } & \multicolumn{2}{|c|}{ Undecided } & \multicolumn{2}{|l|}{ Disagree } \\
\hline & $\begin{array}{l}\text { No. of } \\
\text { respondents }\end{array}$ & $\%$ & $\begin{array}{l}\text { No. of } \\
\text { respondents }\end{array}$ & $\%$ & $\begin{array}{l}\text { No. of } \\
\text { respondents }\end{array}$ & $\%$ \\
\hline Eliminating socio-cultural barriers & 118 & 98 & 2 & 2 & - & - \\
\hline Try to change the attitude of the society & 112 & 93 & 8 & 7 & - & - \\
\hline $\begin{array}{l}\text { Increasing women employees in water } \\
\text { sector }\end{array}$ & 116 & 97 & 4 & 3 & - & - \\
\hline $\begin{array}{l}\text { Giving gender sensitive training for the } \\
\text { community }\end{array}$ & 118 & 98 & 2 & 2 & - & - \\
\hline $\begin{array}{l}\text { Increasing women's educational } \\
\text { qualification }\end{array}$ & 120 & 100 & - & - & - & - \\
\hline $\begin{array}{l}\text { Sharing experiences by creating } \\
\text { management network }\end{array}$ & 118 & 98 & 2 & 2 & - & - \\
\hline Developing women's managerial skill & 120 & 100 & - & - & - & - \\
\hline $\begin{array}{l}\text { Creating opportunities for women to } \\
\text { observe major water committee }\end{array}$ & & & & & & \\
\hline $\begin{array}{l}\text { activities-purposeful involvement of } \\
\text { women in the water commission and } \\
\text { senate meeting }\end{array}$ & 112 & 93 & 8 & 7 & - & - \\
\hline $\begin{array}{l}\text { Training women in relation to the need for } \\
\text { participation in management }\end{array}$ & 114 & 95 & 6 & 5 & - & - \\
\hline $\begin{array}{l}\text { Encouraging women to participate on } \\
\text { managerial positions }\end{array}$ & 114 & 95 & 6 & 5 & - & - \\
\hline
\end{tabular}

Regarding the measures to be taken to enhance women's participation in water resource management, the respondents were asked to point out their degree of agreement. Their response is presented in Table 4.

In addition to the above women's management style, developing women's management skills make women to contribute more for the institutions. Moreover, training on management helps them not to be challenged easily by the impacts of socio-cultural factors like patriarchal ideology of some colleagues. This finding is similar with some measures to be taken on the common wealth countries, where trainings in relation to management were given [13].

According to [13], in England, the Quality of woman in leadership program (QWIL) was established to enhance women's organizational awareness and leadership skills to promote their participation in positions of leadership. Similarly, Endertaworeda water resource and energy bureau is expected to facilitate situations and give training for women related to management skills and related activities.

In general, most of the respondents strongly agree with the given items related to measures to be taken to enhance women's participation in water management.

Accordingly, 96\%, 98\% and $95 \%$ of the respondents pointed out that, increasing women employees in water sector, sharing experiences by creating manage- 
ment network and training for women in relation to the need for participation in management, respectively are measures to be taken to enhance women's participation.

Finally, increasing women's educational qualification and eliminating socio-cultural barriers has been given priority by the questionnaire results and interviewees, so the responsible bodies are expected to realize their achievement, which in turn help to increase the number and quality of women in the water sector and holding of management position. Increasing women's participation in education in general and addressing socio-cultural barriers are long term measures whereas giving training for the existing women in the water sector to develop their management skills and encouraging women, who were not ever participate in management are some of relatively short term measures which can be taken by the responsible bodies of Endertaworeda water resource and energy bureau.

\section{Summary}

In most parts of the world women are the primary users of water resource. As studies from different scholars identified, not only using they manage it during washing (clothes, dishes), bathing, cleaning, cooking and others. Everything that related with sanitation is under control of women and availability of water. The idea and practice of managing water without women participation is unthinkable. Indeed, the study has found that women and girls are often the ones who have to walk long distance and spend many hours every day fetching water which negatively impacts girls schooling and hinders the involvement of women in more productive and income generating activities. Experiences of the district water resource and Energy Bureau and REST revealed that gender has been taken as an important component for the promotion of sustainability of rural water supply and projects. This has created enabling conditions for the promotion of the participation of women and men from the inception till the implementation and monitoring of their water projects. Though women participation and ability is improving through time, members of the communities in the study areas and project staff members both in the village and district level have little confidence on women's water committee members' ability to handle key decision positions such as chairperson-ship. The divisions of work among water committee members have shown that most female committee members were willing to keep the public money, to make sure the water is clean, and to control the hand pump opening time. Furthermore, women often seek employment that allows them the flexibility to spend time with their families. Their putting-family-first frequently prevents their obtaining the training and other credentials they would need to compete more effectively in the job market. Thus it is possible to say that female's end up concentrated in "women's jobs" partly because they choose to do so. But many observers [14] and [15] question whether a women's choice is so free. Therefore, this study concludes that, the socio-cultural factors have an im- 
portant role to block women's choice on care of their family and household activities.

According to the research findings, women's participation in management positions mainly depends on the number of women in the office and also which made the expected proportional representation of women to be insignificant and unsatisfactory. Particularly the absence of well-developed gender policy, the absence of sufficient effort to enhance the number of female staff members are institutional barriers for women's participation in management position of the water sector.

In addition, low educational qualification, the absence of role models and mentoring are the other factors that have high negative influence on women's participation in management position.

Finally, it is pointed out that, the main measure to be taken to enhance women's participation in management is realizing women's access and success in education and increasing the number of women in water resource institutions, which helps to recruit more women in the sector.

Side by side with the above measures, redressing the socio-cultural barriers that affect women educational access and success and their involvement in management is additional measures that can be taken to enhance women's participation in management. Besides this encouraging women, who were not ever participate in management and giving training to develop management skills of women are additional measures to enhance women's participation in water resource management.

\section{Acknowledgements}

Special thanks to all my research participants who shared their time and who provided and assisted me to obtained valuable information.

\section{Conflicts of Interest}

The author declares no conflicts of interest regarding the publication of this paper.

\section{References}

[1] Sandys, E. (2005) Women 2000 and beyond, Published to Promote the Goals of the Beijing Declaration and the Platform for Action. Women and Water, New York.

[2] Ward, A.D. and Elliot, W.J. (1995) Environmental Hydrology. CRC Press, Inc., Boca Raton.

[3] Niala, M., Kusum, A., Mariela, G.V. and Gabriella, R. (2000) Mainstreaming Gender in Water Resources Management; Why and How. Background Paper for the World Vision Process.

[4] Global Water Partnership Technical Advisory Committee (1996) Integrated Water Resource Management, Global Water Partnership.

[5] Rathgeber Eva, M. (2010) Women, Men and Water-Resource Management in Africa. IDRC, Nairobi, Kenya. 
[6] Relief Society of Tigray (2000) Relief Society of TigrayREST Five Year Plan 2001-2005. Summary Prepared for REST Partner Conference, Mekelle.

[7] Seidmekiye, Y. (2008) Academic Women's Participation in Leadership: The Case of Addis Ababa University.

[8] Helgeson, V.S. (2005) Psychology of Gender. 2nd Edition, Pearson, New Jersey.

[9] Nawe, J. (2004) Strategies for Enhancing Female Participation at the University of Dares Salaam, Tanzania.

[10] United Nations Development Program (2003) Mainstreaming Gender in Water Management: A Practical Journey to Sustainability: A Resource Guide. http://www.genderandwater.org/content/download/4545/37857/file/Gender_\%20an d_IWRM_Resource_Guide_complete_200610.pdf

[11] Welch Jr., C.E. (1993) Human Rights and African Women: A Comparison of Protection under Two Major Treaties. Human Rights Quarterly, 15, 549-574. https://doi.org/10.2307/762610

[12] Hill, M.A. and Elizabeth, M.K. (1995) Women's Education and Economic Well-Being. Feminist Economics, 1, 21-46. https://doi.org/10.1080/714042230

[13] Singh, J.K.S. (2002) Women and Management in Higher Education: A Good Practice Hand Book. Paris.

[14] Lott (1987) Sexuality: A Feminist Perspective. In: Kelley, K., Ed., Females, Males, and Sexuality: Theories and Research, SUNY Press, New York, Albany, 175-211.

[15] Fagenson, E.A., Ed. (1993) Women and Work: A Research and Policy Series, Vol. 4. Women in Management: Trends, Issues, and Challenges in Managerial Diversity. Sage Publications, Inc., Thousand Oaks, CA, US. 